\title{
Comunidades lingüísticas y alfabetización digital: una propuesta de análisis del lenguaje en la web
}

\author{
José Luis De Piero(1)
}

(1) Universidad Nacional de

Tucumán.

Centro Interdisciplinario de Investigaciones en Comunicación (CIIC). E-mail: jldp1989@gmail.com

\section{Introducción}

En nuestra realidad presente nos encontramos con un mundo mediatizado por las pantallas, por las herramientas Web, por el uso de celulares, tablas, pizarras y demás artículos inteligentes que, por poseer conexión con Internet, nos permiten ingresar en un universo de información y comunicación que hasta hace unos años era impensado.

Ser docente en esta realidad implica un desafío constante por cuanto las nuevas tecnologías no cesan de crecer, antes bien, al conseguir familiarizarse con una, inmediatamente nos vemos en la necesidad de familiarizarnos con otra nueva, eso sin considerar los constantes cambios en las interfaces de las aplicaciones a las que más o menos nos hemos acostumbrado.

En este contexto hablamos de alfabetización digital, donde necesitamos aprender para poder enseñar y enseñar a aprender, los nuevos modos de comunicación y no sólo porque estos modos y estas herramientas nos permitan mejorar la calidad y la cantidad de los procesos educativos, sino porque los alumnos dominan estos conocimientos antes que los tradicionales. Con esto queremos decir que los alumnos entran en contacto directo antes con las nuevas tecnologías que con la escuela y suelen, desde muy jóvenes, aprender las palabras, los modos, y el léxico propio de aquéllos y, a partir de esto, producir nuevos sentidos. Los adolescentes también han adaptado su caudal léxico, adaptándolo a sus necesidades específicas afectadas por la influencia de las nuevas tecnologías de la información y la comunicación, la frecuencia en el uso de redes sociales y sitios que han desarrollado una comunidad virtual global.

Hasta no hace mucho nos preocupaba la situación de extimidad a la que se veían expuestos los adolescentes, se estaba trasladando la realidad a Internet, creándose mundos paralelos y exhibiendo la intimidad hacia el 
exterior. Hoy la situación se invierte, es el mundo virtual, con sus modos de configurar la información, que se filtra en lo cotidiano.

Nuestra propuesta es, entonces, comprender que existe un discurso Web, es decir, un modo comunicativo con características propias que es necesario estudiar, conocer y aplicar también en el quehacer docente, como parte importante de esta alfabetización digital: Debemos aprender a leer y escribir en este dialecto propio del ciberespacio.

En este trabajo abordaremos algunas cuestiones teóricas alrededor del concepto de alfabetización digital, la complejidad para su definición y como entender la existencia de comunidades lingüísticas permite mejorar la comprensión del discurso con el que se entiende, lee y escribe el mundo. A partir de ello, presentaremos el concepto de meme, que forma parte importante del léxico de los estudiantes y que está asociado con la identidad juvenil actual.

Finalmente, haremos una propuesta de análisis para los sitios y discursos que circulan en la Web, contemplando diferentes niveles y situaciones contextuales y que serviría para desarrollar una herramienta eficaz para la comprensión del discurso en Internet.

\section{Repensar la alfabetización digital desde estudios del discurso}

El concepto de alfabetización digital ha dado lugar a grandes debates por cuanto concierne no sólo al manejo de una computadora sino también al conocimiento sobre el funcionamiento de diversos programas y, más recientemente, el dominio de herramientas Web y aplicaciones relacionadas con la tecnología móvil.

Entenderemos a la alfabetización digital en un sentido general como

las habilidades y competencias de los consumidores finales de los productos de las industrias de las tecnologías de la información y la comunicación. Un intento inicial de definir alfabetización digital, muy citado, (Glister, 1997) identifica las cuatro competencias clave: reunir conocimiento, evaluar la información, buscar y navegar en rutas no lineales $^{(1)}$ (Gillen y Barton, 2010:4).
(1) «the skills and

competencies of those on the receiving end of the products of the ICT industries. (...) An initial often cited attempt at defining digital literacy (Gilster, 1997) identified four key competencies: assembling knowledge, evaluating information, searching and navigating in non-linear routes» (traducción propia). 
Ésta es considerada una propuesta instrumental, donde se pone el acento en los procesos de lectura. Queremos destacar de esta idea el hecho de que en Internet se navega en rutas no lineales. Al respecto, concordamos con Fainholc (2004) cuando afirma:

Leer en Internet constituye la habilidad por excelencia de la sociedad de la información para acceder, interpretar y producir sentidos o significados válidos y valiosos dentro de un registro cultural simbólico nuevo, en términos semiológicos, históricos y tecnológicos, conformados en una red (2004:11).

Este aporte señala la necesidad de aprender a leer para poder aprender a escribir y es que la lectura en la Web ya no es pasiva ni estática como es con un libro en formato papel, necesita de una participación mayor, no sólo en la creación de nuevos sentidos en la subjetividad de la persona, sino en la creación de rutas de lectura que son también rutas de escritura. Esto es posible gracias a la hipertextualidad, una red de textos enlazados por nodos o temas que proponen diversas formas de lectura.

En tanto, Padilla (2012) dice:

El lector, entonces, crea un texto que experimenta como multilineal. Frente al texto del escritor, se construye el texto del lector, en donde él mismo puede elegir entre volver a la exposición del autor o seguir alguna de las conexiones sugeridas por los nexos o enlaces. La versatilidad del hipertexto, entonces, requiere un lector activo. A medida que éste se mueve por una red de textos, desplaza constantemente el centro, y por lo tanto, sus propios intereses pasan a ser el eje organizador (2012:145).

Esta lectura activa requiere una serie de conocimientos y competencias que se deben desarrollar para «navegar» sin perderse, para encontrar información sin «ahogarse» y para poder desarrollar un conocimiento que no sea sólo información.

Esto ha dado lugar a consideraciones sobre la importancia de la escritura en Internet, no se trata solo de ser lectores sino también productores. Arrieta y Montes (2011) afirman: 
Teniendo en cuentas las competencias digitales y de medios, estas involucran un gran número de técnicas de lectura y escritura a través de los espacios en donde los individuos puedan consumir y producir textos digitales (2011:189).

Los componentes de una alfabetización digital incluyen, para estos autores: «Creatividad, pensamiento crítico y evaluación, comprensión social y cultural, colaboración, habilidad para encontrar y seleccionar información, comunicación efectiva, seguridad en Internet, habilidades funcionales» (ídem).

Estos elementos se vuelven fundamentales a la hora de describir lo que entendemos por comunidades lingüísticas:

un ámbito donde se construyen y se concretizan los significados sociales y a su vez constituyen un espacio dentro del cual se generan instituciones no siempre relacionadas de manera armónica, al punto que éstas se manifiestan con un lenguaje que vehiculiza procesos de inclusión o exclusión en formas más o menos explícitas (Cohen de Chervonagura, 2006:11).

Más adelante, esta investigadora señala:

la complejidad simbólica de la ciudad como encuadre físico está superada por otro tipo de red: las comunidades virtuales donde también circulan personas, lenguajes, ideas e imágenes dinámicas con características sui generis porque los Medios Masivos de Comunicación también son lugares de construcción identitaria que inciden en las comunidades lingüísticas y a su vez reflejan un determinado sentido de pertenencia al ser lugares simbólicos si bien, móviles y frágiles, porque el sentido está mediatizado por lo tecnológico (2008:13).

Con esto queremos mostrar la importancia del lenguaje y del discurso en la configuración de comunidades pues los mecanismos de inclusión y exclusión se vuelven manifiestos en formas lingüísticas. Conocer una lengua o un código otorga posibilidades de ingreso a determinados espacios. Además, la comunicación en Internet es fundamentalmente verbal y, por lo tanto, está regida por reglas similares a las que rigen el discurso cotidiano.

Decimos similares porque se incluyen, como ya mencionamos, nuevas reglas que dependen del contexto particular de la comunicación: las reglas de la 
(2) Entendemos por comunidad idiomática al conjunto de personas que hablan una misma lengua histórica: Moreno Fernández (1999: 19-20) hipertextualidad, la multimodalidad y la lectura no lineal y activa, que conducirá a procesos creativos de producción de contenidos.

Estos procesos necesitan que entre los miembros de una comunidad posean una comprensión social y cultural del medio en el que se está trabajando, un trabajo colaborativo con reglas pautadas tácita o explícitamente y un componente comunicativo, que es fundamental para la existencia de comunidades.

Por ello, el modo en el que los grupos sociales se comunican, configurados como comunidades en torno a determinadas prácticas lingüísticas, cambia cuando generan nuevas formas de producción de sentido si éstas están mediadas por las nuevas tecnologías.

En Internet existen diversas comunidades que giran en torno a prácticas discursivas diferentes según la herramienta que empleen. Esto nos permitiría hablar de una comunidad de twitteros, de facebookeros o de youtubers como hasta no hace mucho se hablaba de floggers, y todos ellos producen contenidos de maneras diferentes.

\section{El discurso en la Web: los memes}

Pero un fenómeno más notable en la red es la del surgimiento de un incipiente lenguaje o código lingüístico, más bien, de un conjunto de «lexemas» que son compartidos internacionalmente por todos los usuarios, independientemente de la comunidad idiomática(2) a la que pertenezcan. Con esto queremos hacer referencia al concepto de «fenómeno de Internet», más conocido como «meme». Este término surge con un trabajo del investigador inglés Richard Dawkins en un libro publicado por primera vez en 1976, El gen egoísta. Allí presenta el concepto de meme como un nuevo tipo de replicador, una especie de gen de la cultura o de la memoria. Señala:

Ejemplo de memes son melodías, ideas, frases hechas, prendas de vestir, maneras de hacer cosas, jarrones o arcos de edificios. Al igual que los genes, se propagan en la 
piscina genética saltando de cuerpo a cuerpo a través del esperma o de los óvulos, así también los memes se propagan en la piscina de los memes saltando de cerebro a cerebro a través de procesos que, en un amplio sentido, podemos denominar imitación (Dawkins, 2006:192). ${ }^{(3)}$

Actualmente, el concepto de meme está asociado a fenómenos Web. $A$ guide to Internet memes(4) lo define como:

una idea cultural, sea moda, tecnología o ideología, que se auto-multiplica y esparce entre las personas. Usualmente comparados con genes y evolución, un meme puede sufrir variaciones y mutaciones; pueden extinguirse o evolucionar junto a la sociedad. Un meme de Internet, por otro lado, es una idea que se esparce velozmente a través (...) de Internet. Es lo «viral» en un video «viral».

Estos signos constituyen un código en tanto que son un conjunto de signos asociado a reglas que los determinan y pautan las posibilidades de combinación entre ellos.

Son usados en Internet, principalmente para generar humor, aunque más recientemente se han empleado con otros fines ideológicos. Los signos pueden evolucionar, desaparecer, transformarse y asociarse a otros.

Conocer su existencia, significado y las reglas que los rigen nos permite acceder a un mundo de interpretación y de formulación de significados que es manejado por los adolescentes.

Pero además, contemporáneamente, Lankshear y Knobel (2006) remarcan la relación de los memes con la alfabetización al considerar su dimensión social. Estos autores indican su importancia en relación con la alfabetización digital en sentido general, pues plantean que generar un contenido memético, una viñeta, una imagen alterada, implica competencias que tienen que ver con el manejo de los materiales y de las tecnologías, pero además, tiene que ver con lo que ellos Ilaman Alfabetización con A (en inglés, the big Literacy) puesto que generar un meme implica «generar sentidos, crear significados sociales, y configurar identidades en la vida cotidiana» (Lankshear y Knobel, 2006:220).
(3) «Examples of memes are tunes, ideas, catch-phrases, clothes fashions, ways of making pots or of building arches. Just as genes propagate themselves in the gene pool by leaping from body to body via sperms or eggs, so memes propagate themselves in the meme pool by leaping from brain to brain via a process which, in the broad sense, can be called imitation" (traducción propia).

(4) Infografía disponible en: http://www.skitzone. com/2010/a-guide-to-internetmemes-infographic/ (vista por última vez el 27 de julio de 2013). 
En relación con lo que hemos venido planteando, aquí el concepto de alfabetización en atención a los memes implica procesos sociales de construcción de sentidos, posibles dentro de comunidades que compartan dichos procesos y que implican conocer de qué manera se construyen sentidos. Nuestra propuesta es entender los memes como vehículos de un discurso que es específico de la Web, ya que configuran un código de sentidos, un lexicón o un tesoro de términos por medio de los cuales se pueden construir nuevos significados. Por ejemplo, una persona que incorpora a su vocabulario cotidiano un meme como un lexema fijo: decir «Me siento muy foreveralone hoy» implica, por un lado, entender que este término está asociado a una idea, a un concepto relacionado con la soledad, con la incapacidad de entablar relaciones y, por otro, está ligado a un conjunto de prácticas discursivas como puede ser la navegación y la participación activa en foros o en redes sociales.

\section{El discurso en la Web}

Además de los memes, existen reglas específicas empleadas en cada sitio Web para la comunicación. Facebook, Twitter, Youtube y los blogs, consideramos, son espacios privilegiados donde los adolescentes pasan gran parte de su tiempo. En estos sitios, principalmente Facebook, se producen nuevas palabras que son trasladadas al lenguaje cotidiano como vimos en el ejemplo anterior.

Cuando hablamos de lenguaje o discurso en la Web, entonces, nos referimos a las diferencias que posee el modo comunicativo de un usuario respecto al modo «cotidiano» o «fuera de línea». Esto es, las limitaciones propias de un género Web (como puede ser, por ejemplo, Twitter) nos obligan a modificar elementos de nuestra enunciación para adecuarla al género y en atención a las comunidades de práctica o comunidades interpretativas a las que pertenezcamos.

Por ello, partiendo de una descripción de los elementos propios del género Web del que hablemos, podremos ver en ellos cómo deben adaptarse el modo comunicativo y luego los rasgos específicos que las comunidades aportan. 
(1) El código empleado: en general, en la Web se emplea el código verbal escrito, pero a esto puede (y debe) sumársele también la presencia de emoticones y, más recientemente, la incorporación de lo que denominamos el "código memético», como conjunto de lexemas y formas de comprensión del universo Web. El código, como sabemos, no es siempre homogéneo (Cf. Kerbrat, 1980) ni externo, sino que los usuarios se apropian y generan usos particulares, por ello, considerar cuál es el código empleado es un paso necesario para interpretar desde dónde habla cada usuario en cada Web.

(2) Oralidad vs. escritura: en este sentido, nos parece oportuno seguir la propuesta de Oesterreicher (2004), quien afirma que son extremos de un continuum del cual existen diversos grados y así podemos pensar en géneros que se encuadrarían, por ejemplo, en lo escrito-hablado y géneros dentro de lo hablado-escrito.

(3) Sincronía vs. asincronía: lo separamos por el hecho de que muchos géneros admiten diversos manejos del tiempo en términos de la velocidad para responder y de la duración de los comentarios. A esto sumamos los aportes de David White, Not-quite real time, que nosotros tradujimos por Tiempo real diferido.

Para este investigador, lo nuevo de la asincronía en la Web es la aceptabilidad cultural de tener un margen de entre 10 segundos y 10 horas para contribuir en una discusión o en una conversación (aunque entre 10 segundos y alrededor de 5 minutos es el rango de tiempo más interesante) (2012).

Con esto, los tiempos aceptables para una respuesta varían según cada sitio.

(4) La posibilidad de recibir respuesta: es un dato menor pues algunos usuarios lo admiten o no, conforme las propias configuraciones de privacidad en cada sitio.

(5) Las redes hipertextuales: en general, hay producciones Web que pueden valerse por sí mismas en su contexto mientras que hay otras que están forzosamente ancladas a un conjunto hipertextual que las determina. 
(6) La posibilidad de modificarse o corregirse: un video en Youtube no tiene posibilidad de ser modificado como una entrada en un blog, por ejemplo.

Asimismo, debemos considerar los diferentes niveles de estructuración del lenguaje para realizar un análisis más exhaustivo. Proponemos tener en cuenta los siguientes niveles, siguiendo parcialmente a Gianmatteo y Albano (2012).

(1) Nivel fonético-ortográfico: según se trate de oralidad o escritura, y de qué manera ambas aparecen mezcladas en los diversos géneros, principalmente en el chat, donde la grafía está asociada a la expresión y donde incluso se buscan formas de representar los rasgos suprasegmentales del lenguaje.

(2) Nivel morfológico: de qué manera se crean neologismos a partir de los términos nuevos y de los nuevos sitios.

(3) Nivel sintáctico: hay sitios que admiten mayor complejidad oracional que otros. En un chat, por ejemplo, no se esperan oraciones subordinadas.

Nivel léxico: quizás sea el nivel más rico para el análisis, las nuevas palabras, las frases lexicalizadas y de qué manera éstas pasan al lenguaje cotidiano.

(4) Nivel semántico: en relación con el nivel anterior, muchas palabras son resemantizadas en la Web. «Visto» no es sólo un participio, sino que también implica una actitud ante la información gracias a Facebook.

(5) Nivel pragmático: en un estudio más profundo, considerar las formas de tratamiento, la cortesía en la Web o netiquette, el ciberbullying, entre otros temas, entrarían en este nivel.

Estos elementos nos permitirían el abordaje de cualquier espacio y nos permitirían realizar una descripción profunda, tanto para manejar los sitios con mayor eficacia como para ponerlos en práctica en el aula y enseñarlos efectivamente. 


\subsection{Ejemplo de análisis}

Para mostrar cómo funcionaría la propuesta mencionada proponemos un ejemplo de análisis de los videoblogs o vlogs (como un tipo de producción propia de Youtube, un género discursivo particular iniciado en esa Web y producido para ella), trabajado en De Piero (2012).

En primer lugar, cuando hablamos de videos estamos hablando de la posibilidad de incluir, dentro de la filmación, contenidos que afiancen o que releven lo que se presenta en la pantalla, en ese sentido, se manejan múltiples códigos diversos, relacionados con, entre otras cosas, las prácticas populares propias de cada cultura. Así, la vestimenta será más o menos significativa según el tipo de video: hay momentos donde el vlogger (quien hace los videos) decide mostrarse vistiendo camisa y corbata para denotar madurez, frente a otra escena donde se mostrará vistiendo remera y una gorra para denotar inmadurez.

En segundo lugar, entendemos que los videos están acompañados por títulos, descripciones y comentarios de usuarios, como texto escrito que acompaña a cada vlog y que forman parte del vlog en tanto género (Cf. Burgess, 2011:5). Por ello, en una página de Youtube, el título se encontrará por encima del video, la descripción por debajo del mismo y, según la comunidad, hará referencia al contenido del video (como es el caso de la comunidad inglesa) o hará referencia a contenidos externos al video (como es el caso de la comunidad latinoamericana).

También pensamos en que la relación entre oralidad y escritura se da de manera difusa, hay elementos marcadamente orales, hay elementos escritos, pero la producción en sí misma se asemeja a lo que Oesterreicher (2004) propone como lo escrito hablado: el vlog tiene un pre-texto del cual se basa uno nuevo, oral, filmado y grabado, que permanecerá en la Web por tiempo indefinido, posee una distancia temporal desde el momento al momento de la recepción, esperando asincrónicamente sus respuestas, por ejemplo, en los comentarios. Con esto, queremos indicar que muchas veces el vlog se basa en un guión más o menos elaborado a partir del cual los vloggers crean el video. Esto último, junto a los videos recomendados, crea redes hipertextuales de «lectura» de videos, poniendo en relación, a veces aleatoriamente, a veces a partir de las preferencias del usuario, diferentes producciones multimediales. Sin embargo, como en un libro, no existe la posibilidad de modificar el conte- 
nido una vez publicado, sí de eliminarlo, pero no de editarlo, restringiendo algunas posibilidades con ello.

Respecto de los niveles de análisis de la lengua, según se trate de inglés, español o la lengua que sea, corresponde identificar a qué variedad de la misma corresponde, sin embargo, en términos de léxico, hay elementos que se generalizan, y se extienden más allá de los límites propios de cada lengua, como puede ser las referencias al espacio de la página, que es común a la práctica, las referencias al botón de suscripción (antes reconocido como un botón amarillo y que dio lugar a muchos lexemas relacionados con dicho color), por ello, muchos usuarios hablan de dejar comentarios «debajo» o downbelow, se refieren a compartir, share, dar un "me gusta» o un like y piden siempre que se suscriban al canal para aumentar la cantidad de seguidores.

Finalmente, en cuanto al nivel pragmático, podemos pensar en algunas reglas propias de cada variedad de habla, como los actos de habla predominantes para cada sección del video o como la cortesía lingüística diferenciada para cada variedad propia. Es más frecuente encontrar segmentos de saludo de bienvenida y de despedida en los vlogs ingleses que en los blogs en español, junto con segmentos de pedidos de disculpa con relación a la poca frecuencia de subida de videos, dando cuenta de la pertenencia a la comunidad.

\section{Conclusión}

En este breve trabajo hemos intentado presentar un conjunto de cuestiones teóricas que marque una hoja de ruta para abordar una cuestión principal: el discurso, o el modo de comunicarse en el ciberespacio.

Partiendo del concepto de alfabetización digital, quisimos mostrar la importancia de sumar a estos conocimientos, pues según cómo los usuarios se comuniquen en la Web, implicará diferencias en el modo de comprender la realidad de sus comunidades lingüísticas.

Si pensamos que la escuela es también una comunidad lingüística, no podemos dejar de lado la intervención de factores externos que modifican los comportamientos lingüísticos dentro de la institución y que por lo tanto alteran de alguna manera el modo de nombrar, comprender, leer y escribir la realidad. 
Ante esto presentamos el concepto de meme, o fenómeno de Internet, como una herramienta necesaria para aproximarse al discurso juvenil pues es un componente clave del léxico de los usuarios.

Una vez realizado ese recorrido, hicimos una propuesta teórica de un marco de análisis para abordar los diferentes espacios y herramientas Web desde una perspectiva de los estudios del discurso. Esta herramienta permitiría un estudio desde el área, específico, para tratar cuestiones discursivas en el aula, por ejemplo, analizar las diferencias entre oralidad y escritura y como ellas se difuminan en la Web, pero también permitiría, a partir de un estudio más profundo, ofrecer estrategias acordes para emplear estas herramientas con diversos fines.

Internet es sin lugar a dudas un espacio de interacción humana, por encima de los procesos tecnológicos implicados. En tanto tal, la comunicación se vuelve un factor fundamental para el desarrollo de dichas interacciones. Conocer los modos más eficaces de dicha comunicación, los lexemas preferidos, las reglas que lo rigen nos permite formar parte de las comunidades que allí nacen y se desarrollan.

Quedará para otras investigaciones ver la interacción de este modelo con docentes y alumnos en situaciones concretas. Esperamos nuestro aporte entregue una herramienta más para el desarrollo de una efectiva alfabetización digital. 


\section{Referencias bibliográficas}

Arrieta-Carrascal, A. y Montes, V. (2011). Alfabetización digital: uso de las TIC's más allá de una formación instrumental y una buena infraestructura. En Revista Colombiana de Ciencias Animales 3(1):180-197.

Burgess, J. (2011). YouTube. En Oxford Bibliographies Online. Oxford University Press.

Cohen de Chervonagura, E. (2006). Comunidades lingüísticas: Confines y trayectorias (Vol. I). Tucumán. Universidad Nacional de Tucumán.

Cohen de Chervonagura, E. (2008). Comunidades lingüísticas: Confines y trayectorias (Volumen II). Tucumán. Universidad Nacional de Tucumán.

Dawkins, R. (2006 [1976]). The selfish gene. Great Britain: Oxford University Press.

De Piero, J. L. (2012). Las comunidades lingüísticas en los vlogs de YouTube: Estudio contrastivo de casos. San Miguel de Tucumán. Tesis inédita.

Fainholc, B. (2004). Lectura crítica en Internet. Análisis y utilización de los recursos tecnológicos en educación. Rosario: Homo Sapiens.

Giammatteo, M. y H. Albano. La palabra en la red: características lingüísticas de la comunicación en Internet. En Giammatteo, M. y H. Albano (Coords.). El léxico. De la vida cotidiana a la comunicación cibernética. Buenos Aires: Biblos.
Kerbrat-Orecchioni, C. (1980). La enunción. De la subjetividad en el lenguaje. Buenos Aires: Hachette. Knobel, M. y Lankshear, C. (2007). Online memes, Affinities, and Cultural Production. En Knobel M. y Lankshear, C. (Ed.). A new literaciessampler: New literacies and digital epistemologies 29, 199-227.

Moreno Fernández, F. (1999). Principios de sociolingüística y sociología del lenguaje. Barcelona: Ariel. Oesterreicher, W. (2004). Textos entre inmediatez y distancia comunicativas. El problema de lo hablado escrito en el Siglo de Oro. En Cano Aguilar, R. (Coord.). Historia de la Lengua Española. Barcelona: Ariel.

Padilla, C. (2012). Gramática del español: Perspectivas actuales: Taller de reflexión sobre el lenguaje. Córdoba: Comunicarte.

White, D. (2012). The future is not quite real-time. Disponible en: http://tallblog.conted.ox.ac.uk/index. php/2012/07/05/the-future-is-not-quite-real-time/ (consultado por última vez el 25 de julio de 2013). 